\title{
Synthesis of ionic liquid-based deep eutectic solvents for extractive desulfurization of fuel
}

Wei Jiang ${ }^{1}$, Hongping $\mathrm{Li}^{2}$, Chao Wang ${ }^{2}$, Wei Liu ${ }^{2}$, Tao Guo ${ }^{2}$, Hui Liu ${ }^{2}$, Wenshuai Zhu ${ }^{2}$, Huaming $\mathrm{Li}^{1}{ }^{*}$

${ }^{1}$ Institute for Energy Research, Jiangsu University, 301 Xuefu Road, Zhenjiang 212013, P. R. China

${ }^{2}$ School of Chemistry and Chemical Engineering, Jiangsu University, Zhenjiang 212013, P. R. China

*Corresponding author: Tel.:+86-511-88791800; Fax: +86-511-88791708; E-mail address: zhuws@ujs.edu.cn; lihm@ujs.edu.cn 


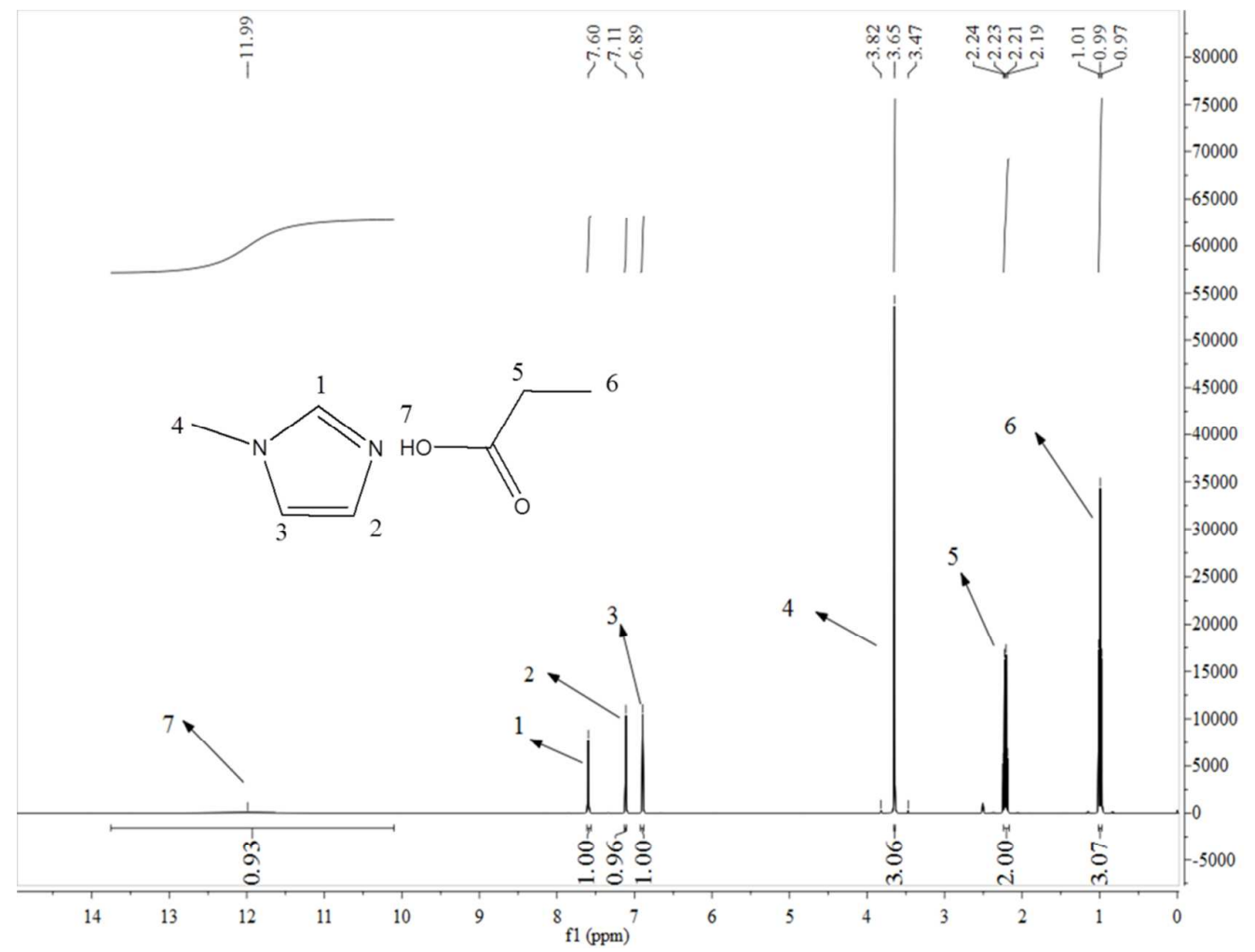

Figure $\mathrm{S} 1{ }^{1} \mathrm{H}$ NMR of MIM/PA.

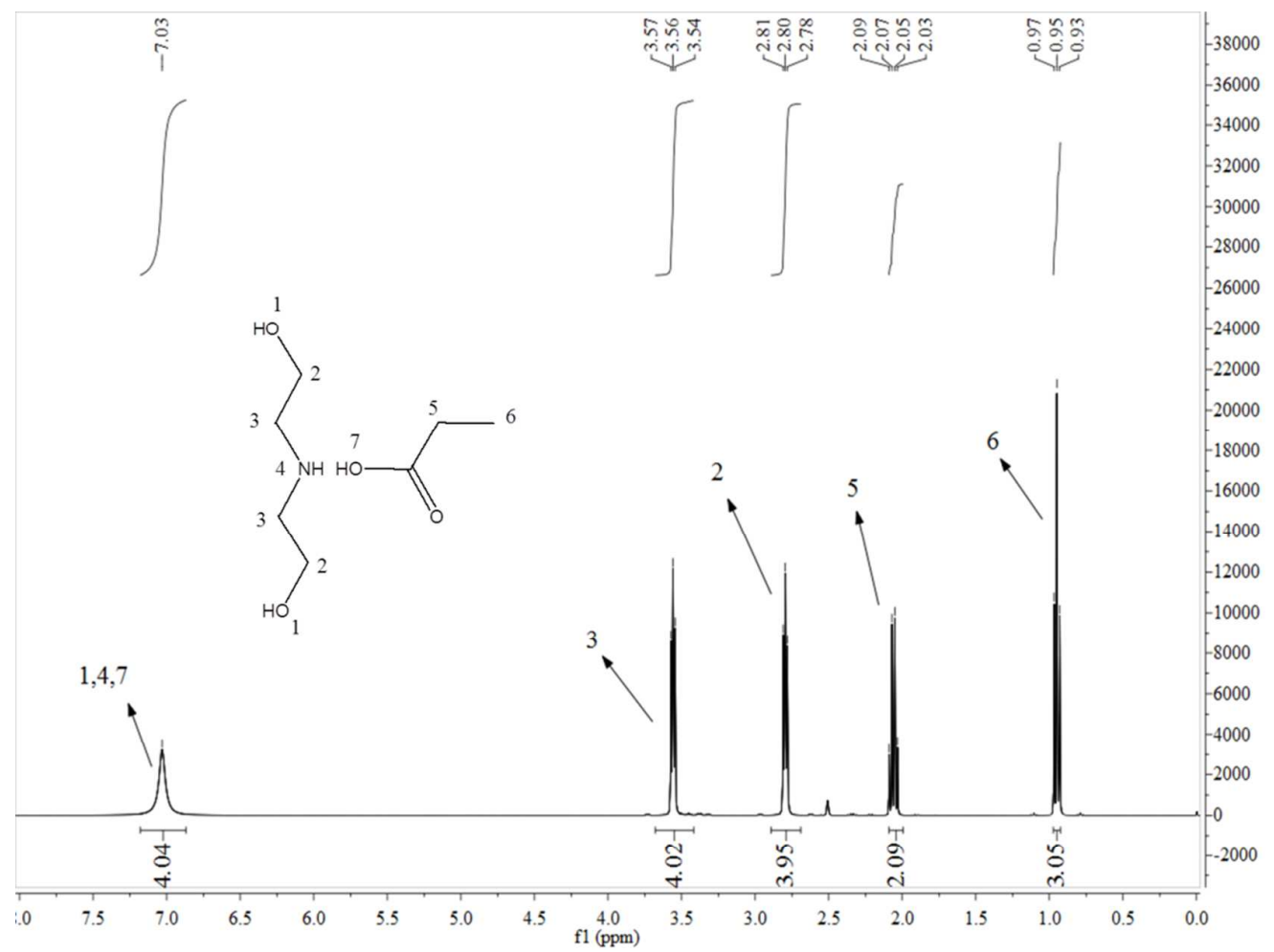

Figure S2 ${ }^{1} \mathrm{H}$ NMR of DEA/PA. 


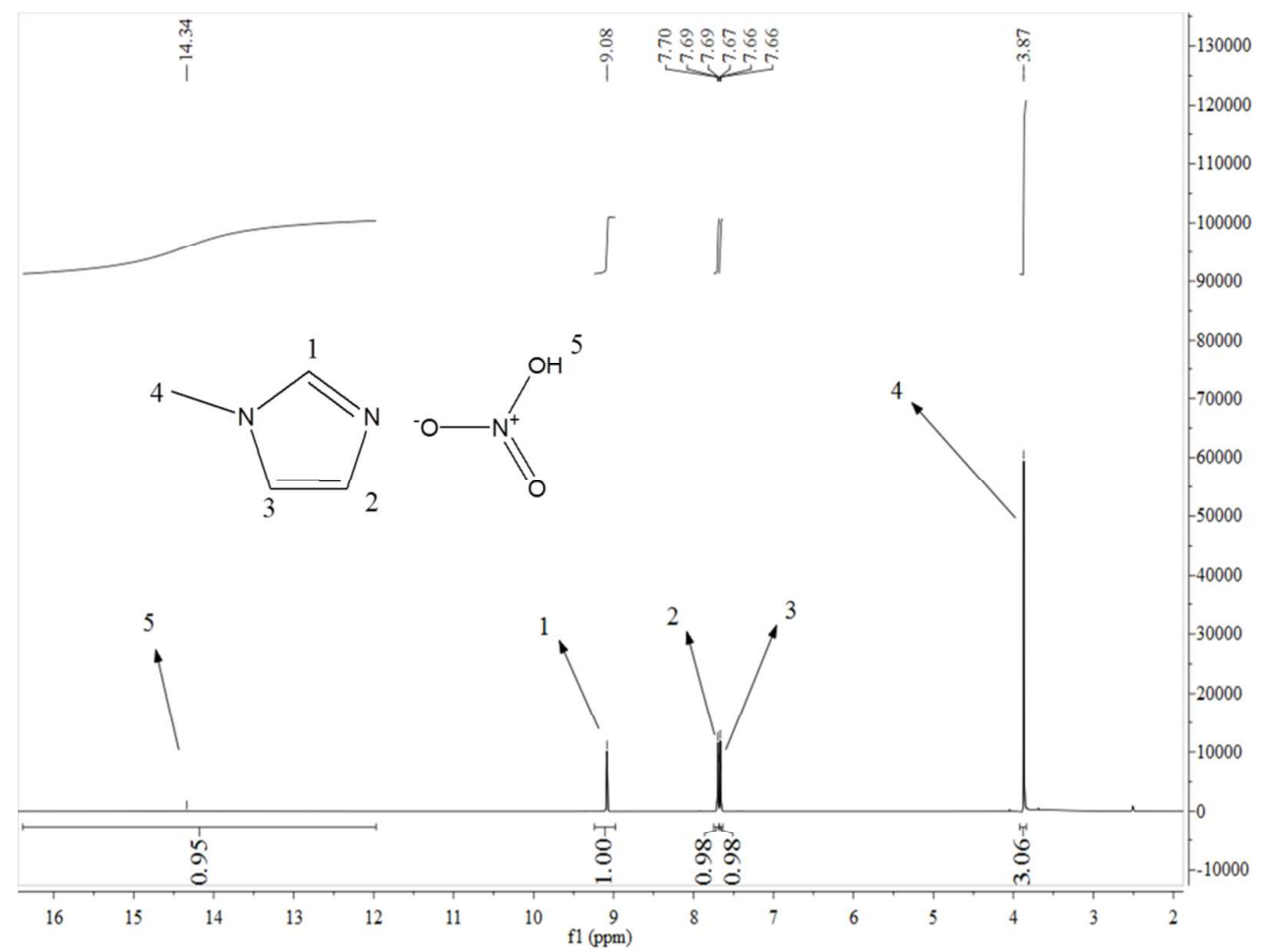

Figure S3 ${ }^{1} \mathrm{H}$ NMR of MIM/NA.

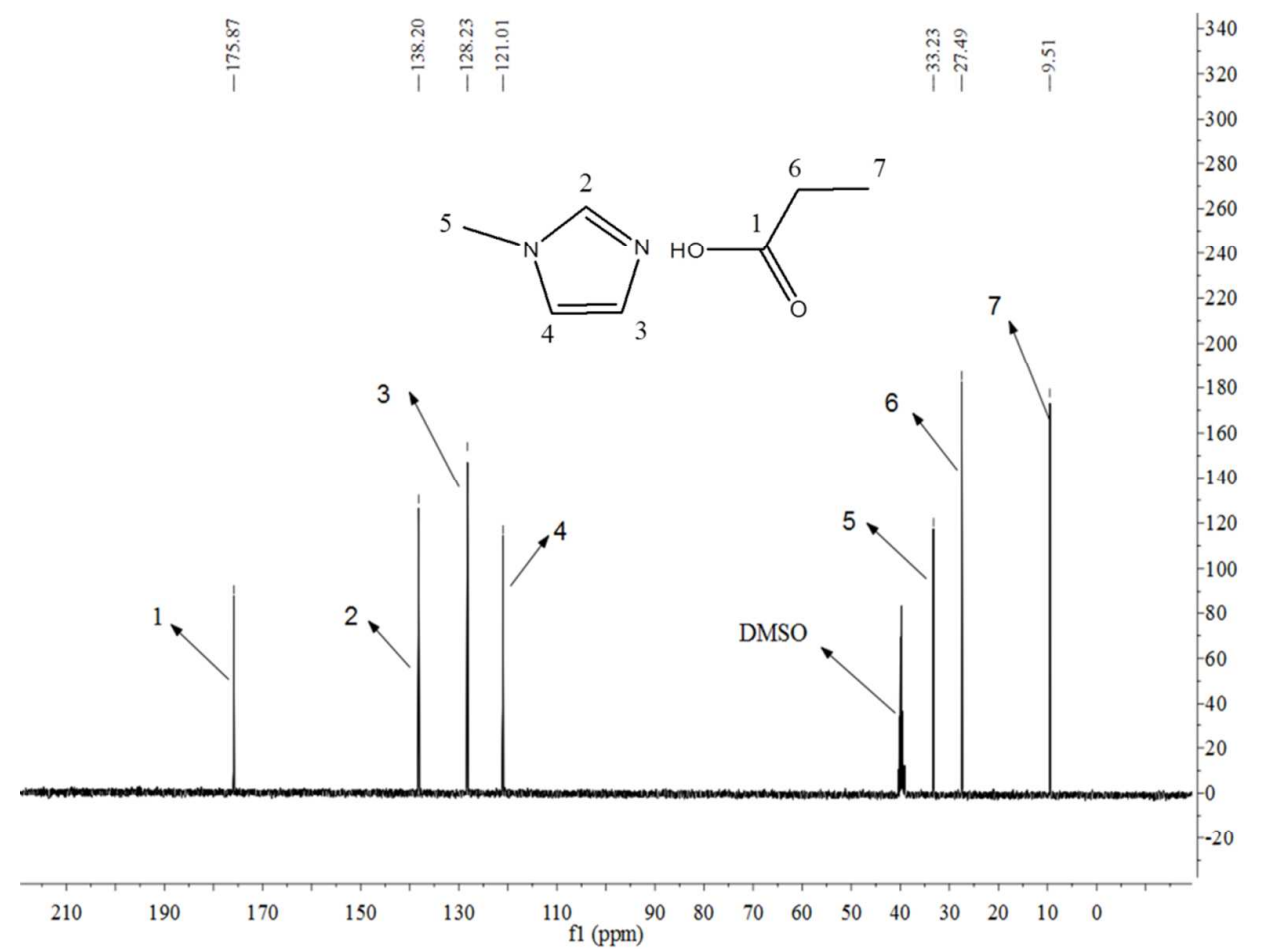

Figure S4 ${ }^{13} \mathrm{C}$ NMR of MIM/Pr. 


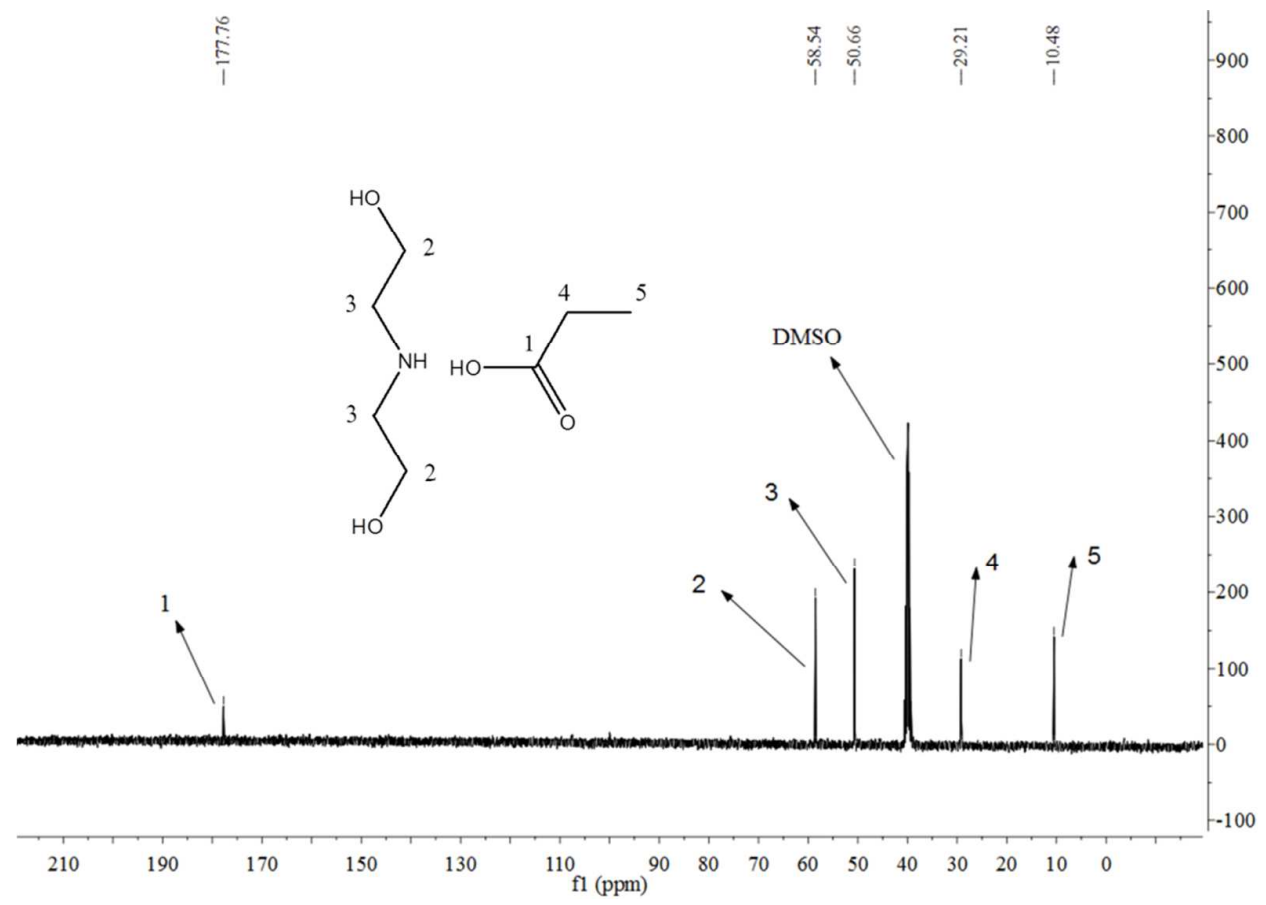

Figure. S5 ${ }^{13} \mathrm{C}$ NMR of DEA/PA.

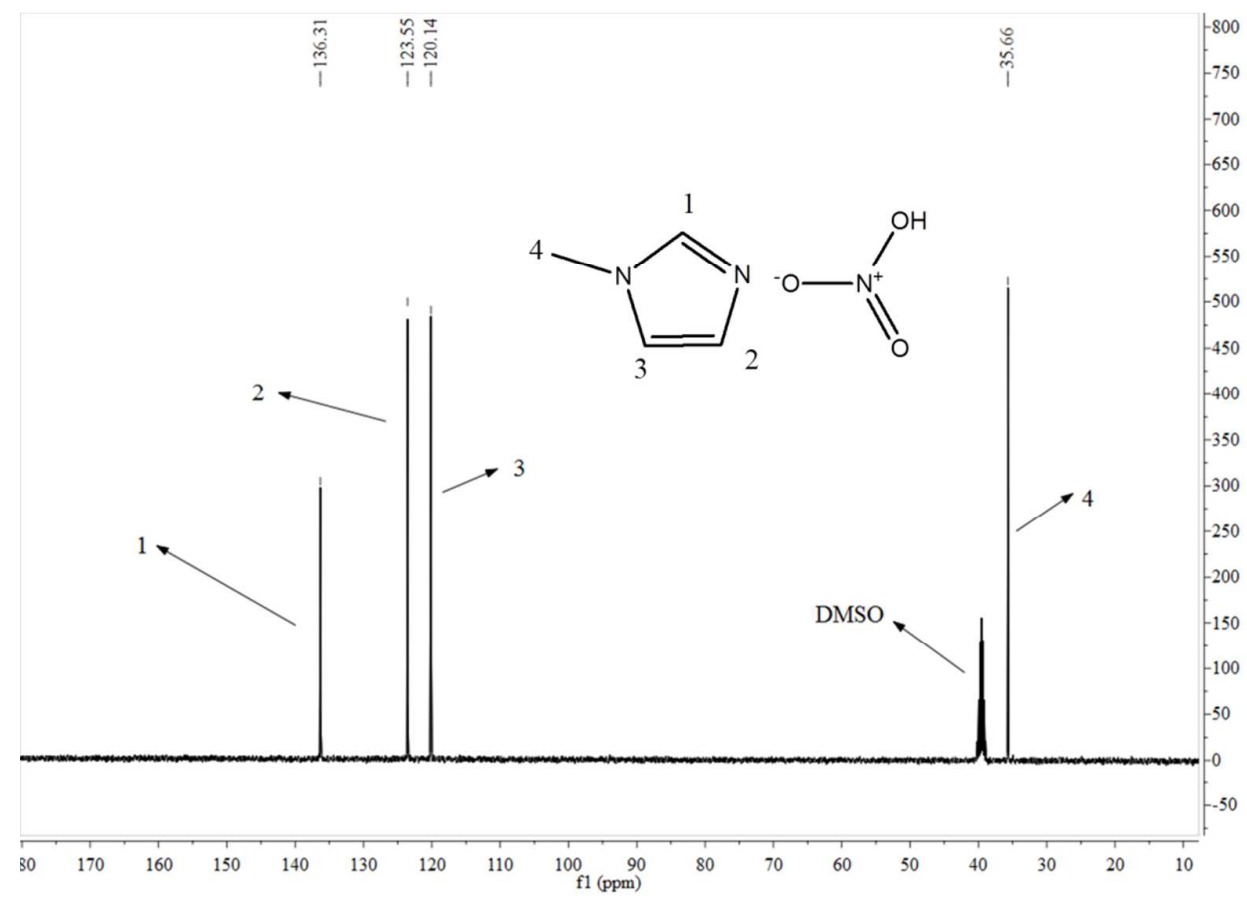

Figure S6 ${ }^{13} \mathrm{C}$ NMR of MIM/NA. 


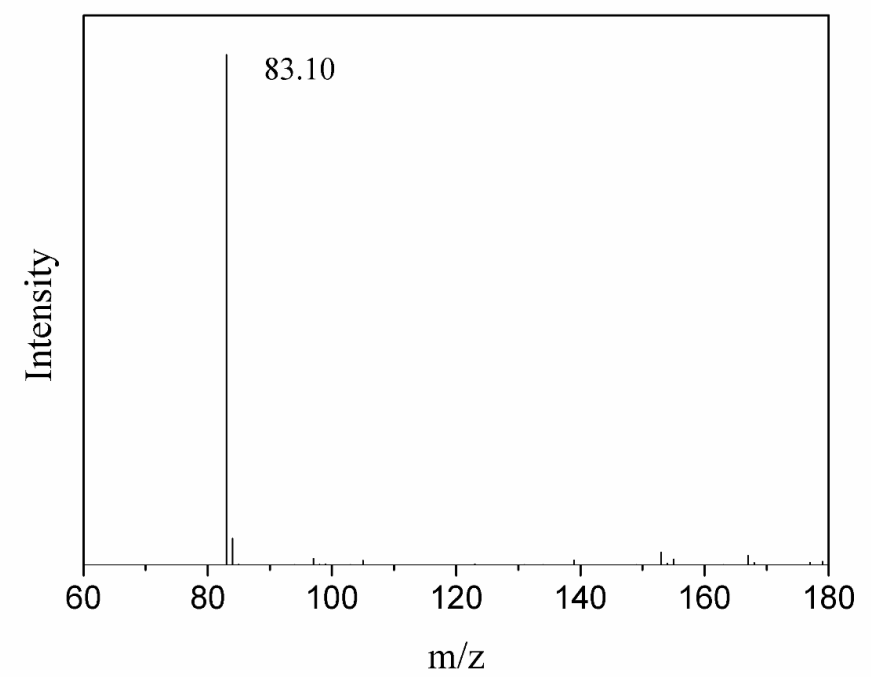

Figure S7 Positive ESI-MS of MIM/PA.

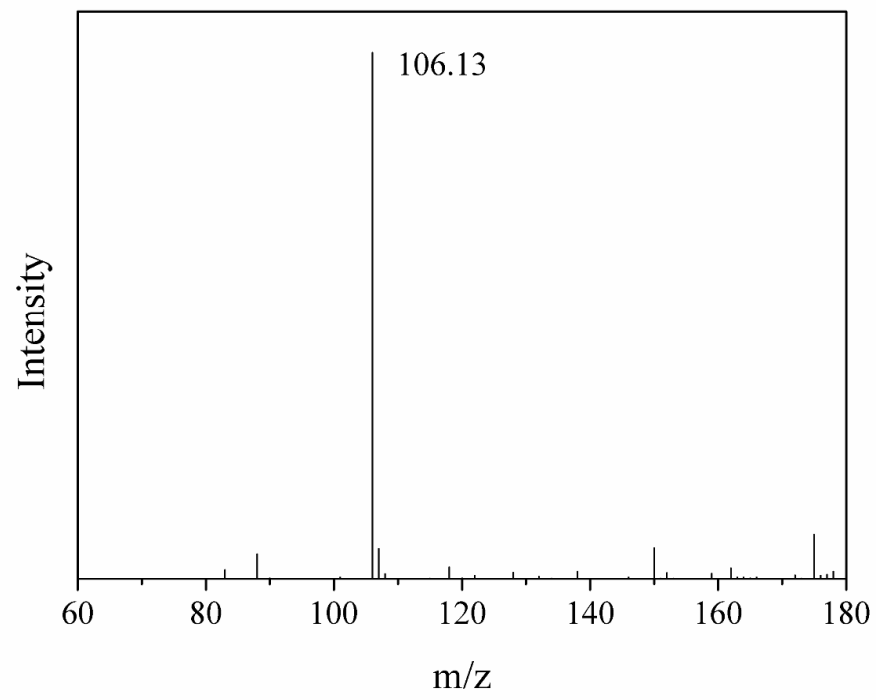

Figure S8 Positive ESI-MS of DEA/PA. 


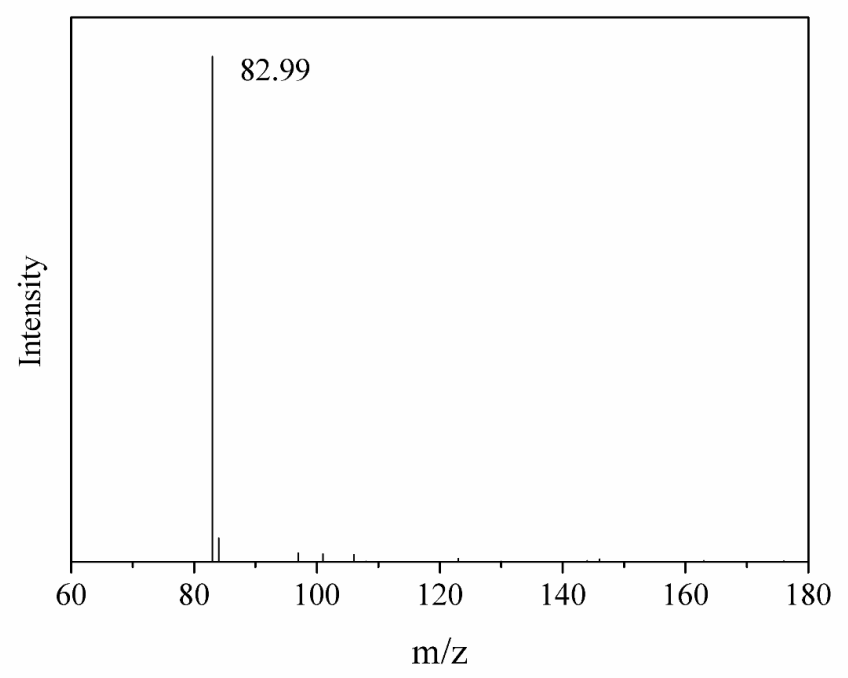

Figure S9 Positive ESI-MS of MIM/NA. 